\title{
Giant aortic root aneurysm after aortic valve replacement
}

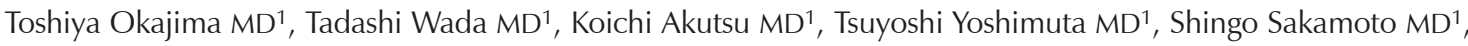
Yuiichi Tamori MD¹, Hiroshi Tanaka MD², Masahiro Higashi $\mathrm{MD}^{3}$, Satoshi Takeshita MD
\end{abstract}

\begin{abstract}
A
29-year-old man on chronic hemodialysis underwent aortic valve replacement for severe aortic regurgitation. The aortic valve was tricuspid and the ascending aorta was not dilated. Thirteen years later, he was referred to the National Cardiovascular Center (Suita, Osaka, Japan) due to aortic root aneurysm. Transthoracic echocardiography showed a markedly enlarged aortic root with normal prosthetic valve function. Computed tomography scanning revealed a giant aortic root aneurysm with a maximum diameter of $87 \mathrm{~mm}$ (Figure 1). The patient subsequently underwent a successful aortic root replacement and Bentall procedure.

A previous study reported that nearly $30 \%$ of patients having aortic valve replacement would eventually receive aortic repair for enlargement of the aortic root and ascending aorta (1). Cystic medial degeneration constitutes the major underlying pathology in these
\end{abstract}

patients (2). In our patient, pathological examination revealed a moderate degree of cystic medial degeneration in the aortic specimens excised at the time of the second operation. For patients with cystic medial degeneration, careful longitudinal follow-up is recommended after aortic valve replacement regardless of whether the valve is bicuspid or tricuspid.

\section{REFERENCES}

1. Natsuaki M, Itoh T, Rikitake K, Okazaki Y, Naitoh K. Aortic complications after aortic valve replacement in patients with dilated ascending aorta and aortic regurgitation. J Heart Valve Dis 1998;7:504-9.

2. Isselbacher EM. Thoracic and abdominal aortic aneurysms. Circulation 2005;111:816-28.
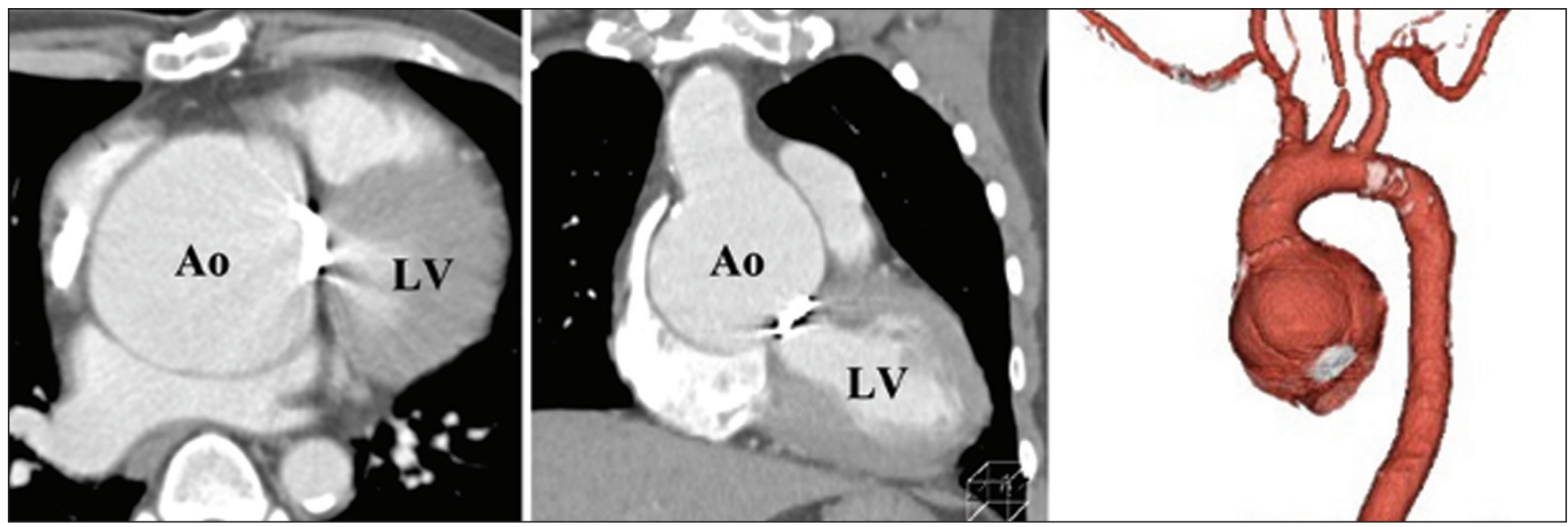

Figure 1) Computed tomography scanning revealing a giant aortic root aneurysm with a maximum diameter of $87 \mathrm{~mm}$. Ao Aorta; LV Left ventricle

${ }^{1}$ Department of Cardiology; ${ }^{2}$ Department of Cardiovascular Surgery; ${ }^{3}$ Department of Radiology, National Cardiovascular Center, Suita, Osaka, Japan Correspondence and reprints: Dr Satoshi Takeshita, Department of Cardiology, National Cardiovascular Center, 5-7-1 Fujishiro-dai, Suita, Osaka

565-8565, Japan. Telephone 81-6-6833-5012, fax 81-6-6833-9865, e-mail stake@muse.ocn.ne.jp

Received for publication March 5, 2008. Accepted April 6, 2008 